\title{
Identifikasi Distribusi Beban Sedimentasi pada Intake DAM dan Reservoir PLTA (Studi Kasus: PLTA Cirata, Purwakarta - Jawa Barat)
}

\author{
Asep Irwan ${ }^{1}$, Ari Wicaksono ${ }^{1}$, Firda Aulia Khairin ${ }^{1}$ \\ Teknik Sipil, Fakultas Teknik dan Desain, Institut Teknologi Sains Bandung, Cikarang, Indonesia \\ E-mail: asep.irwan@itsb.ac.id \\ ariwicaksono@gmail.com \\ firdaaulia22@gmail.com
}

Informasi naskah:

Diterima

20 Desember 2019

Direvisi

15 Januari 2020

Disetujui terbit

14 Februari 2020

Diterbitkan

28 Februari 2020

\begin{abstract}
Reservoirs in Indonesia are almost inseparable from the problem of sedimentation. Sedimentation issues are important in reservoir operations, including those that affect reservoir life. One of them is in the PLTA Cirata which experienced a high amount of sedimentation, based on the results of research by BPWC in 2017 the value of sedimentation was 1.96 million m3/year. The results obtained 1,565,844.51 m3/ year so that when compared with this value has a difference between $394,155.49 \mathrm{~m} 3$ / year, this occurs because of differences in the sedimentation calculation method. The research method uses the MIKE 21 Module (Flow Model), this research can provide information related to the sedimentation load in the PLTA Cirata. Sediment load that occurs in the intake area of the modeling results is from the Cikundul watershed with a maximum flow value in one year in 2018 of $716.14 \mathrm{~m} 3 / \mathrm{s}$ occurred in April. As for the thickness of sediment occurs first 1-month simulation results in the location of each estuary is between 0.01 to $0.15 \mathrm{~m}$ for the location of the dam area of 0.01 to $0.03 \mathrm{~m}$. The thickness of sediments in the Cirata area at the location of the river mouth is around $\pm 1.8 \mathrm{~m} /$ year and at the dam around $\pm 0: 36 \mathrm{~m} /$ year. Types of sediment in each river mouth obtained $21.21 \%$ sand, $78.48 \%$ silt, and $0.31 \%$ gravel, for the dam area obtained $24.49 \%$ sand, $75.08 \%$ silt, and $0.43 \%$ gravel. It can be concluded that sedimentation entering the Intake area is removing sediment from each watershed namely Cikundul, Cibalagung, Cisokan, Citarum, and Cicendo.
\end{abstract}

Keyword: reservoirs, sedimentation, PLTA Cirata, watersheds 


\subsection{PENDAHULUAN}

\subsection{Latar Belakang}

Permasalahan sedimentasi di waduk menjadi sangat penting karena sedimentasi mengganggu operasional waduk dan mempengaruhi umur fungsi waduk. Dalam waktu yang lama sedimentasi ini akan menimbulkan pendangkalan yang signifikan. Jika tidak ditangani secara bertahap maka nilai manfaat waduk akan berkurang khusunya untuk PLTA. Penelitian ini mengambil studi kasus di waduk Cirata. Waduk Cirata merupakan salah satu waduk kaskade yang terdapat di DAS Citarum. Waduk Cirata mengalami penambahan sedimentasi yang cukup signifikan setelah beroperasi selama 25 tahun sejak penggenangan pada tahun $1987^{1}$. Berdasarkan pengamatan di lapangan, waduk Cirata secara umum sudah mengalami alih fungsi lahan konservasi menjadi lahan budidaya. Perkembangan keramba jaring apung (KJA) semakin banyak. Berdasarkan data yang diperoleh dari Satgas Citarum Harum Sektor 12, pada bulan Mei hingga Juni 2018 terdapat sekitar 98.397 KJA di waduk Cirata. Jumlah itu mengalami peningkatan dibandingkan Desember tahun 2016 dengan total 77.169 KJA. Hal ini tidak sebanding dengan SK Gubernur Jawa Barat Nomor 41 tahun 2002, bahwa jumlah total KJA di waduk Cirata tidak boleh lebih dari 12.000 unit KJA. Hal pokok yang menjadi penyebab utama permasalahan waduk Cirata yaitu pertama berkaitan dengan faktor ekologis, dan kedua berkaitan dengan regulasi. Mengingat bahwa waduk Cirata mempunyai fungsi sebagai pembangkit listrik yang sangat dibutuhkan oleh masyarakat, maka penting untuk mempertahankan agar operasi waduk memiliki umur yang lama. Penelitian ini terfokus pada identifikasi seberapa besar beban sedimentasi yang terjadi di intake waduk Cirata. Metode yang digunakan dalam penelitian ini adalah simulasi sedimentasi menggunakan software MIKE 21. Data kalibrasi menggunakan data lapangan, yaitu pengambilan sampel air dan sedimen dasar.

\subsection{Maksud dan Tujuan}

Maksud dari penelitian ini adalah untuk:

1. Mengidentifikasi kondisi eksisting dan jumlah endapan sedimen (bed load) berdasarkan hasil simulasi di waduk Cirata.

2. Melakukan analisis beban sedimentasi sebagai upaya masukan dan bahan pertimbangan dalam menentukan kebijakan pengelolaan waduk Cirata.

Tujuan dari penelitian ini adalah untuk:

1. Melakukan analisis hidrodinamika sebagai data inputan model sedimentasi yang akan dibangun pada software MIKE 21.

2. Membangun sebuah model sedimentasi di area waduk Cirata sebagai dasar acuan dalam perhitungan umur layan waduk. 


\subsection{Ruang Lingkup}

Dalam penelitian ini, ruang lingkup kajian meliputi pemodelan sedimentasi di area PLTA waduk Cirata untuk mengidentifikasi laju beban sedimentasi yang terjadi serta mengukur endapan sedimen dasar (bed load) pada intake DAM dan reservoir area PLTA waduk Cirata. Simulasi sedimentasi menggunakan modul software MIKE 21 sebagai tools untuk pemodelan.

\subsection{Dasar Pemodelan MIKE 21}

Mike 21 adalah suatu perangkat lunak rekayasa profesional yang berisi sistem pemodelan yang komprehensif untuk program komputer dalam 2D free-surface flows. Mike 21 dapat diaplikasikan sebagai simulasi hidrolika dan fenomena terkait di sungai, danau, estuari, teluk, pantai dan laut. Program ini dikembangkan oleh DHI Water \& Environment. Persamaan pengatur dalam modul Mike 21 yaitu sebagai berikut ${ }^{2}$ :

1. Modul Hidrodinamika

Modul hidrodinamik dalam Mike 21 HD adalah sistem model numerik umum untuk muka air dan aliran di estuari, teluk dan pantai. Model ini mensimulasi aliran dua dimensi tidak langgeng dalam fluida satu lapisan (secara vertikal homogen). Persamaan berikut konservasi massa dan momentum, menggambarkan aliran dan perbedaan muka air:

$$
\begin{aligned}
& \frac{\partial \zeta}{\partial t}+\frac{\partial p}{\partial x}+\frac{\partial q}{\partial y}=\frac{\partial d}{\partial t} \\
& \frac{\partial p}{\partial t}+\frac{\partial}{\partial x}\left(\frac{p^{2}}{h}\right)+\frac{\partial}{\partial y}\left(\frac{p q}{h}\right)+g h \frac{\partial \zeta}{\partial x}+\frac{g p \sqrt{p^{2}+q^{2}}}{c^{2} \cdot h^{2}}-\frac{1}{\rho_{w}}\left[\frac{\partial}{\partial x}\left(h \tau_{x x}\right)+\frac{\partial}{\partial y}\left(h \tau_{x y}\right)\right]-\Omega_{\mathrm{q}}- \\
& \mathrm{fVV}_{\mathrm{x}}+\frac{h}{\rho_{w}} \frac{\partial}{\partial x}\left(p_{a}\right)=0 \\
& \frac{\partial q}{\partial t}+\frac{\partial}{\partial y}\left(\frac{q^{2}}{h}\right)+\frac{\partial}{\partial x}\left(\frac{p q}{h}\right)+g h \frac{\partial \zeta}{\partial y}+\frac{g p \sqrt{p^{2}+q^{2}}}{c^{2} \cdot h^{2}}-\frac{1}{\rho_{w}}\left[\frac{\partial}{\partial y}\left(h \tau_{y y}\right)+\frac{\partial}{\partial x}\left(h \tau_{x y}\right)\right]-\Omega_{\mathrm{p}}- \\
& \mathrm{fVV}_{\mathrm{y}}+\frac{h}{\rho_{w}} \frac{\partial}{\partial x y}\left(p_{a}\right)=0
\end{aligned}
$$

Dimana, h $(\mathrm{x}, \mathrm{y}, \mathrm{z})$ kedalaman air, $\mathrm{d}(\mathrm{x}, \mathrm{y}, \mathrm{z})$ kedalaman air dalam berbagai waktu $(\mathrm{m}), \zeta$ $(\mathrm{x}, \mathrm{y}, \mathrm{z})$ elevasi permukaan $(\mathrm{m}), p, q(x, y, t)$ flux density dalam arah $\mathrm{x}$ dan $\mathrm{y}\left(\mathrm{m}^{3} / \mathrm{s} / \mathrm{m}\right)$, (uh,vh), (u,v) depth averaged velocity dalam arah $\mathrm{x}$ dan $\mathrm{y}, p_{a}(x, y, t)$ tekanan atmosfer $\left(\mathrm{kg} / \mathrm{m} / \mathrm{s}^{2}\right), \rho_{w}$ merupakan berat jenis air $\left(\mathrm{kg} / \mathrm{m}^{3}\right), x, y$ yaitu koordinat ruang $(\mathrm{m}), C(x, y)$ tahanan Chezy $\left(\mathrm{m}^{1 / 2} / \mathrm{s}\right), g$ adalah percepatan gravitasi bumi $=9.81\left(\mathrm{~m} / \mathrm{s}^{2}\right)$, $f(V)$ faktor gesekan angin, dan $\tau_{x x}, \tau_{x y}, \tau_{y y}$ yaitu komponen effective shear stress.

2. Modul Mud Transport

Modul Mud Transport (MT) merupakan aplikasi model dari angkutan sedimen kohesif. MIKE 21 Flow Model FM adalah satu sistem modeling berbasis pada satu pendekatan mesh fleksibel. Dikembangkan untuk aplikasi di dalam oceanographic, rekayasa pantai dan alam lingkungan muara sungai. Modul Mud Transport menghitung hasil dari pergerakan material kohesif berdasarkan kondisi aliran di dalam 
modul hidrodinamik. Persamaan pengatur yang digunakan dalam modul ini adalah sebagai berikut:

$\frac{\partial z}{\partial t}=\frac{z\left(1+a-e^{z}\right)}{e^{z}(z-1)+1} \frac{1}{U_{0}} \frac{d U_{0}}{d t}+\frac{30 K}{k} \frac{\sqrt{K^{2} U_{0}^{2}+z^{2} U_{f 0}^{2}+2 K z U_{f 0} U_{0} \cos \gamma}}{e^{z}(z-1)+1}$

$\mathrm{K}$ adalah konstanta Von Karman, $\mathrm{t}$ adalah waktu, $\mathrm{z}$ adalah parameter tebal boundary layer, $\mathrm{U}_{0}$ adalah kecepatan orbit dasar gelombang terdekat, $\mathrm{U}_{\mathrm{f} 0}$ adalah kecepatan geser arus dalam lapisan batas gelombang, $\mathrm{k}$ adalah kekasaran dasar permukaan, $\mathrm{d}_{50}$ adalah rata ukuran diameter, dan $\mathrm{k}_{\mathrm{R}}$ adalah ripple yang berkaitan dengan kekasaran. Beberapa item output yang dihasilkan dari Modul Mud Transport (MT) ini, yaitu Suspended Sediment Concentration (SSC), Deposition Rate, Rate of bed level change, dan Bed level change.

\section{METODOLOGI}

Metode yang digunakan dalam penelitian ini adalah menggunakan software MIKE 21 dengan modul Flow Model dimana dalam modul tersebut sudah termasuk modul hidrodinamik dan modul sedimentasi.

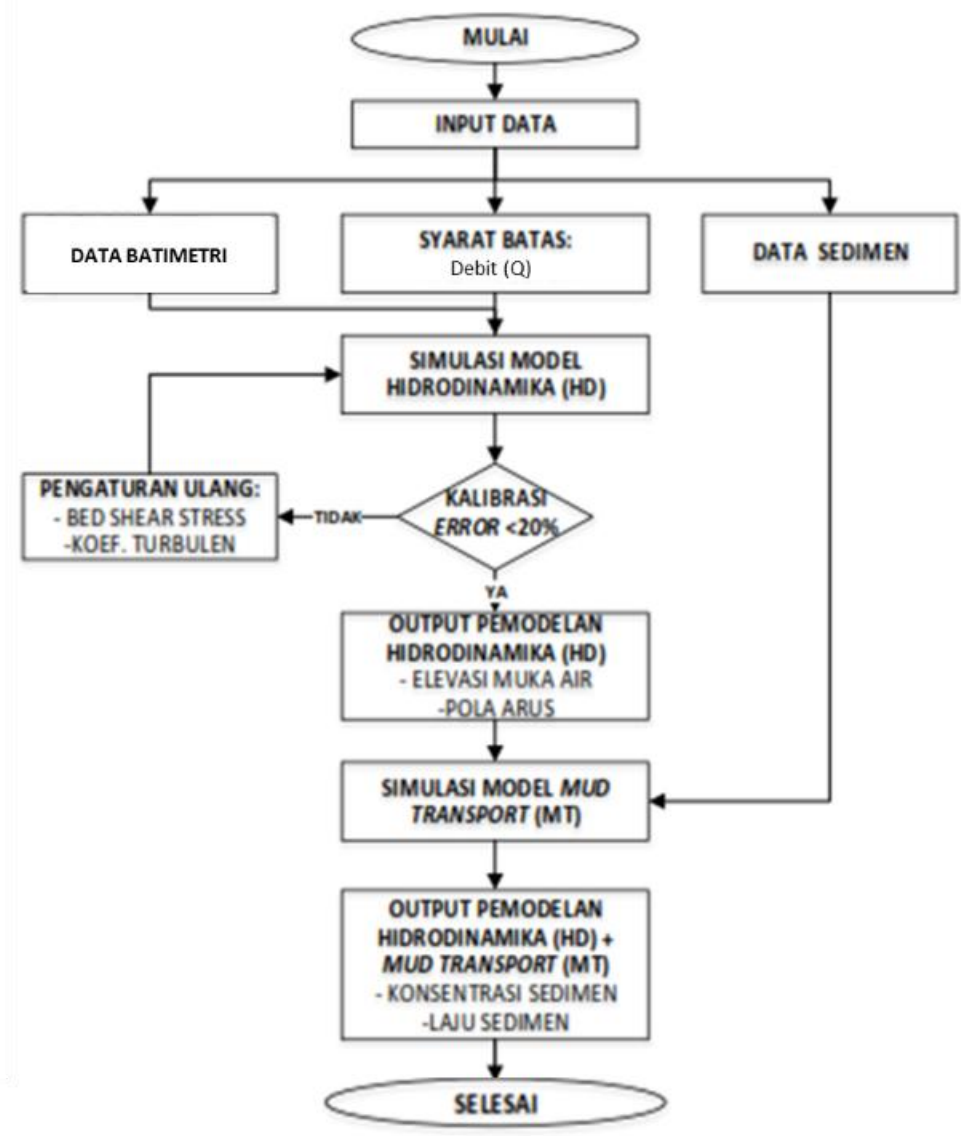

Gambar 1. Diagram alir proses pemodelan MIKE 21 


\subsection{Syarat Batas Model}

Syarat batas model yang digunakan, yaitu sebagai berikut:

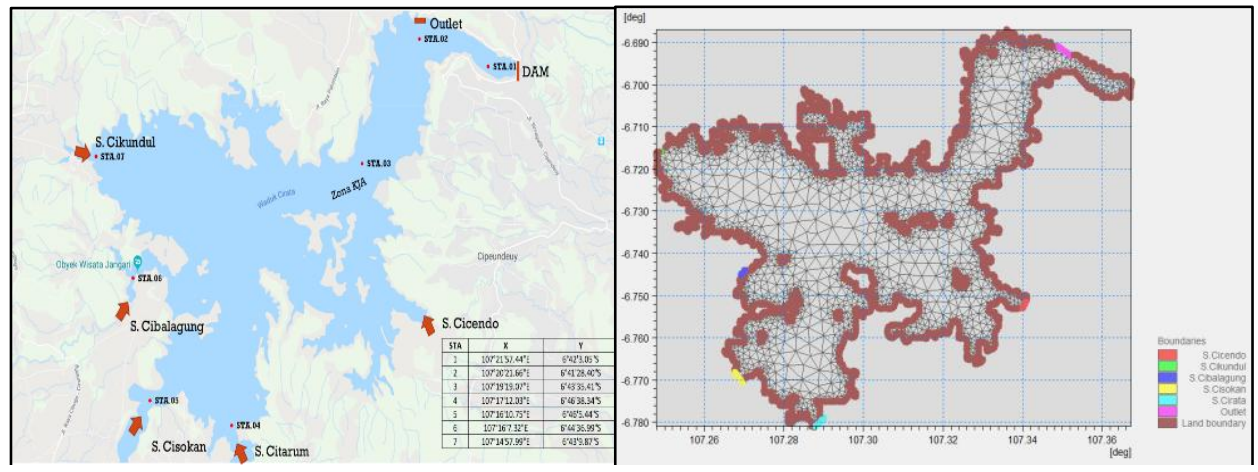

Gambar 2. Syarat batas model sedimentasi

\subsection{Konfigurasi Model}

Konfigurasi pemodelan dilakukan sebagai perancangan persiapan sebelum melakukan proses pemodelan dengan modul hidrodinamikan dan transportasi sedimen sebagai berikut:

Tabel 1. Konfigurasi Module Hydrodynamic dan Mud Transport

\begin{tabular}{cc}
\hline Parameter & Value \\
\hline Specification file & RunModelHD.m21fm \\
Simulation Period & 2018-01-01 $00: 00-2018-12-31$ 00:00 (1 Year) \\
Time step interval & $86400 \mathrm{~s}$ \\
No. of time steps & 364 \\
HD : OUTPUT & HD : AreaHD.dfsu \\
Specification file & RunModelMT.m2 $1 \mathrm{fm}$ \\
MT: Water Column Parameter & Deposition, Critical Shear Stress; Constant: $0.01 \mathrm{~N} / \mathrm{m}^{2}$ \\
MT: Bed Parameter & Erosion, Critical Shear Stress; Constant: $0.03 \mathrm{~N} / \mathrm{m}^{2}$ \\
MT : OUTPUT & MT : AreaMT.dsfu \\
\hline
\end{tabular}

\subsection{Pengambilan Sampel Sedimen}

Pengambilan sampel sedimen melayang dan sedimen dasar dilakukan di beberapa titik lokasi sumber sedimen yaitu di muara-muara sungai dan di area KJA waduk Cirata. Pengambilan menggunakan alat Bottle Nensen untuk sampel air dan Grab Sampler untuk sedimen dasar. Berikut dokumentasi pengambilan sampel di lapangan:

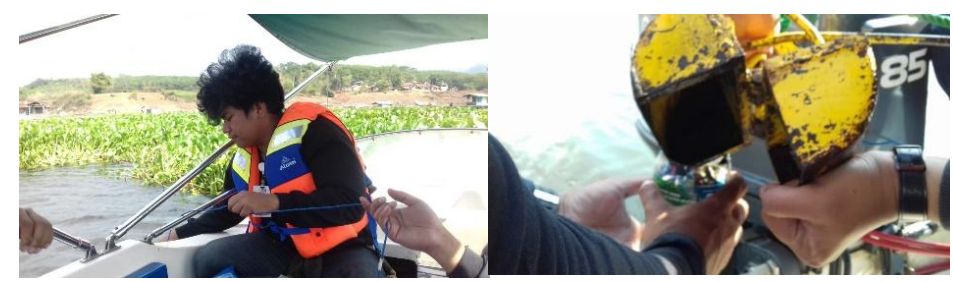

(a)

(b)

Gambar 3. (a) Pengambilan sampel; (b) Sedimen dasar (Bed Load)

(Sumber: pengamatan lapangan, 2019) 
Sampel-sampel dianalisis di laboratorium untuk diuji dan diidentifikasi berdasarkan butirannya. Hasil analisis lab menunjukkan jenis sedimen di waduk Cirata, yaitu sebagai berikut:

Tabel 2. Resume hasil pengujian sedimen

\begin{tabular}{ccccc}
\hline & \multicolumn{4}{c}{ Grain Size Analysis (Analisa Butir) } \\
\cline { 2 - 5 } Area Sampel & $\begin{array}{c}\text { gravel } \\
\text { ( kerikil ) }\end{array}$ & $\begin{array}{c}\text { sand } \\
(\text { pasir })\end{array}$ & $\begin{array}{c}\text { silt } \\
\text { (lanau })\end{array}$ & $\begin{array}{c}\text { clay } \\
\text { ( lempung })\end{array}$ \\
\cline { 2 - 5 } & $(\%)$ & $(\%)$ & $(\%)$ & $(\%)$ \\
\hline Intake & 0.43 & 24.49 & 75.08 & 0.00 \\
Muara & 0.31 & 21.21 & 78.48 & 0.00 \\
\hline
\end{tabular}

\section{PEMBAHASAN DAN DISKUSI}

Berdasarkan hasil simulasi pemodelan yang dilakukan, didapatkan tipe material sedimen jenis lanau atau sejenis lumpur sehingga modul yang digunakan dalam MIKE 21 adalah Mud Transport.

\subsection{Pola Model Hidrodinamika}

Dari pemodelan yang telah dilakukan terjadi proses hidrodinamik pada waduk Cirata. Batasan yang didefinisikan dalam model di antaranya kondisi muka air awal pada keseluruhan waduk adalah $+0 \mathrm{~m}$, kemudian level muka air normal di outlet didefinisikan sebesar -2 m. Pola pergerakan hidrodinamika dengan menggunakan data debit time series berdasarkan stasiun pengamatan yang dilakukan oleh Badan Pengelola Waduk Cirata pada tahun 2018 yaitu sebagai berikut:

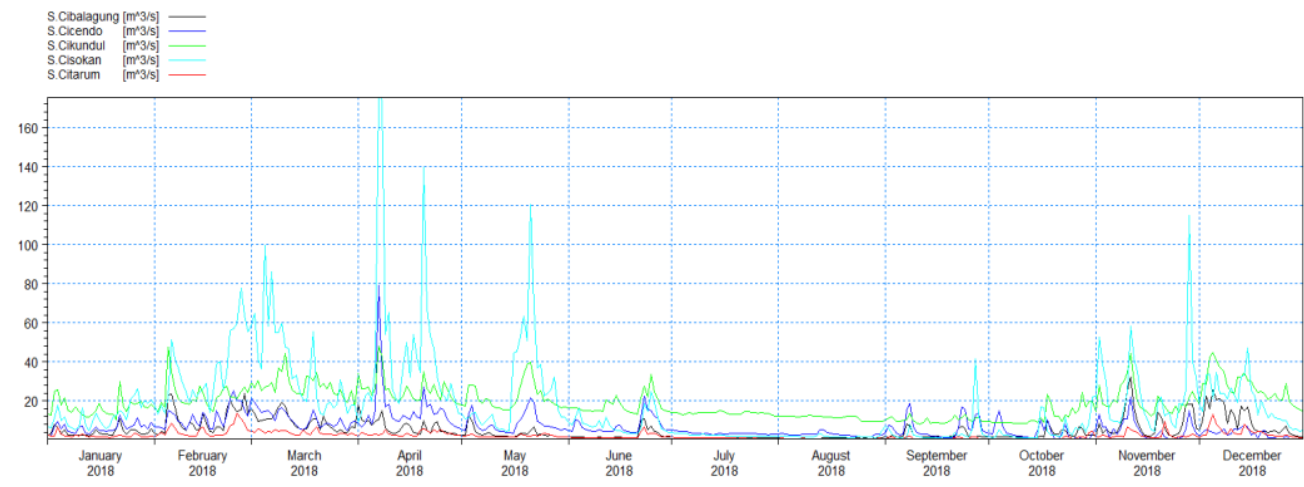

Gambar 4. Data debit hasil pengamatan Badan Pengelolaan Waduk Cirata

Berdasarkan hasil pemodelan hidrodinamika, kecepatan arus di sekitar waduk relatif kecil sedangkan perubahan tinggi muka air terjadi dominan di areal dekat muara-muara sungai. Hal ini dikarenakan adanya pertemuan arus muara dengan kondisi besaran volume air di waduk Cirata, dimana kecepatan arus di sekitar muara berkisar $0.005-0.008 \mathrm{~m} / \mathrm{s}$, sedangkan pada area bendungan memiliki kecepatan arus yang sangat tergantung pada pintu intake PLTA. 

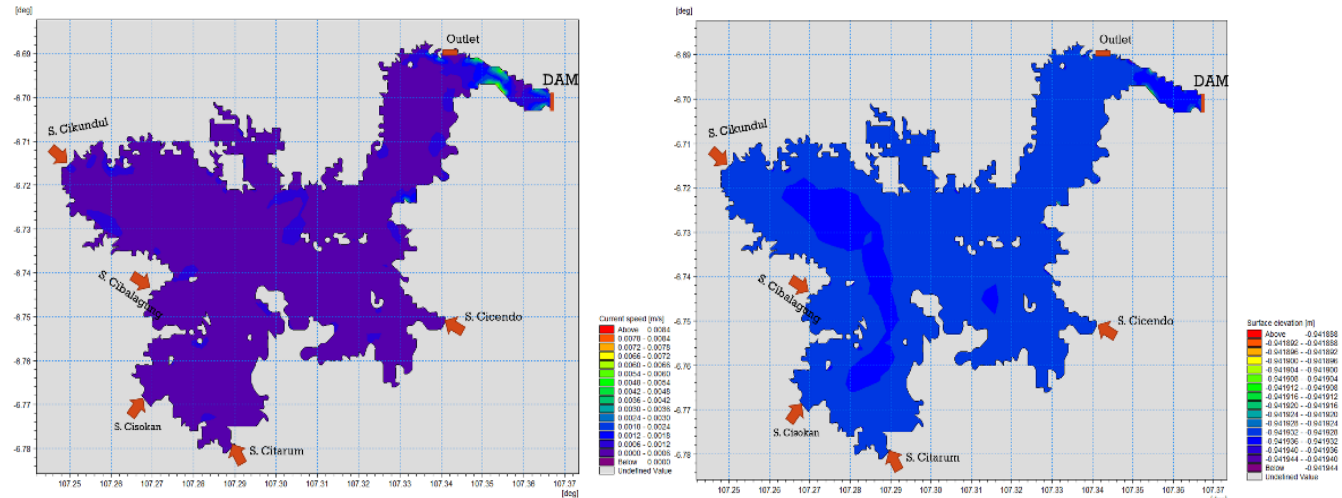

Gambar 5. (a) Pola kecepatan arus. (b) Tinggi muka air di waduk Cirata (Sumber: Hasil Analisa Penelitian)

\subsection{Pola dan Laju Sebaran Sedimentasi}

Pola sebaran sedimentasi sangat dipengaruhi oleh pergerakan massa air yang bergerak dari setiap muara sungai yang masuk ke waduk Cirata. Hal ini diartikan sebagai pergerakan dari partikel sedimen di layer air pada periode waktu tertentu. Terpisah dari kondisi hidrodinamik, gerakan partikel sedimen tergantung pada karakteristik material yang terangkut seperti ukuran butiran, kecepatan jatuh butiran, dan sebagainya. Hasil simulasi menunjukkan pola sebaran sedimen bergerak menuju pada intake bendungan yang di sana merupakan outlet untuk PLTA Waduk Cirata.

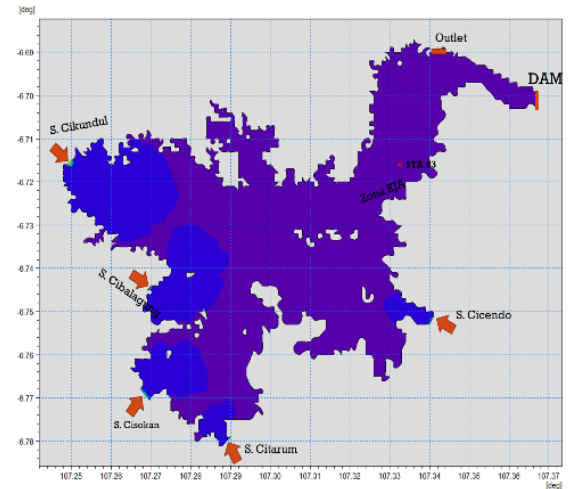

(a)

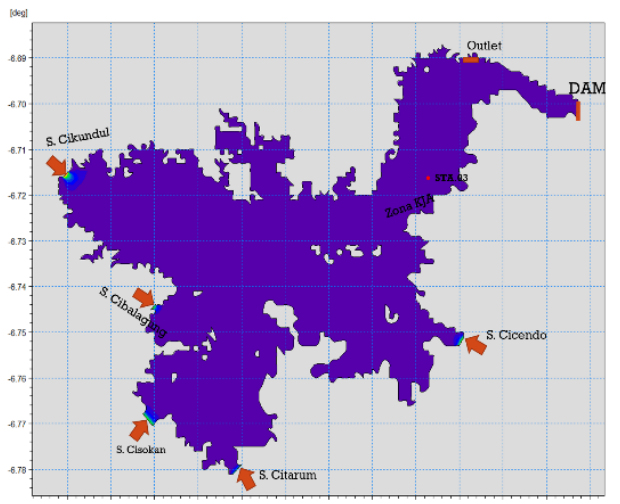

(b)

Gambar 6. (a) Total ketebalan sedimentasi. (b) Total laju sedimentasi di waduk Cirata (Sumber: Hasil Analisa Penelitian)

Pola sebaran sedimentasi dari setiap muara sungai terlihat memberikan beban sedimentasi kepada waduk Cirata. Beban sedimentasi terbesar datang dari DAS sungai Cikundul karena memiliki debit yang lebih besar daripada muara sungai lainnya. Besaran nilai beban sedimentasi berdasarkan simulasi satu bulan pertama di lokasi setiap muara yaitu berkisar antara $0.01-0.15 \mathrm{~m}$. Namun untuk di lokasi area bendungan berkisar $0.01-$ $0.03 \mathrm{~m}$. Nilai ini apabila dikalikan dalam satu tahun maka ketebalan sedimen di area waduk Cirata pada lokasi muara sungai berkisar $\pm 1.8 \mathrm{~m} /$ th dan di bendungan berkisar \pm 
$0.36 \mathrm{~m} / \mathrm{th}$. Apabila kita meninjau dari luasan area dengan laju sedimentasi maka didapatkan nilai total keseluruhan sedimentasi selama satu tahun simulasi yaitu $1,565,844.51 \mathrm{~m}^{3} /$ th. Berdasarkan hasil kajian yang dilakukan oleh pihak Badan Pengelola Waduk Cirata pada tahun 2017 tingkat laju sedimentasi rata-rata sebesar 1.96 juta $\mathrm{m}^{3} /$ tahun.

\subsection{Analisa Beban Sedimentasi}

Analisa beban sedimentasi dilakukan pada lokasi intake atau sekitar bendungan waduk Cirata berdasarkan syarat batas yang sudah dibangun dalam model. Beban sedimentasi terbesar yang masuk pada area intake, menurut hasil pemodelan sedimentasi, datang dari DAS sungai Cikundul dengan nilai debit maksimum dalam satu tahun sebesar $716.14 \mathrm{~m}^{3} / \mathrm{s}$ yang terjadi pada bulan April tahun 2018. Selain itu juga hasil identifikasi jenis sedimen yang terdapat di intake waduk Cirata memiliki jenis sedimen yang sama dengan beberapa DAS yang dijadikan sebagai syarat batas yaitu $75.08 \%$ lanau dan $24.49 \%$ pasir.

\section{KESIMPULAN}

Kesimpulan yang didapatkan dari hasil penelitian yaitu sebagai berikut:

1. Jenis sedimen di area setiap muara sungai yang masuk ke waduk Cirata adalah $21.21 \%$ pasir, $78.48 \%$ lanau dan $0.31 \%$ krikil. Sedangkan di area intake PLTA adalah $24.49 \%$ pasir, $75.08 \%$ lanau dan $0.43 \%$ pasir. Dapat disimpulkan bahwa sedimentasi yang masuk ke area intake merupakan sedimen yang bergerak dari setiap DAS sungai Cikundul, Cibalagung, Cisokan, Citarum dan Cicendo.

2. Ketebalan sedimen yang terjadi hasil simulasi satu bulan pertama di lokasi setiap muara yaitu berkisar antara $0.01-0.15 \mathrm{~m}$. Namun untuk di lokasi area bendungan berkisar $0.01-0.03 \mathrm{~m}$. Nilai ini apabila dikalikan dalam satu tahun maka ketebalan sedimen di area waduk Cirata pada lokasi muara sungai berkisar $\pm 1.8 \mathrm{~m} / \mathrm{th}$ dan di bendungan berkisar $\pm 0.36 \mathrm{~m} / \mathrm{th}$.

3. Total sedimentasi hasil simulasi satu tahun didapatkan $1,565,844.51 \mathrm{~m}^{3} /$ th. Sedangkan berdasarkan hasil kajian yang dilakukan oleh pihak Badan Pengelola Waduk Cirata pada tahun 2017 tingkat laju sedimentasi rata-rata sebesar 1.96 juta m3/tahun. Hasil simulasi menunjukkan nilai yang tidak jauh berbeda.

4. Beban endapan sedimentasi terbesar yang terjadi pada area intake adalah dari DAS sungai Cikundul dengan nilai debit maksimum dalam satu tahun sebesar $716.14 \mathrm{~m}^{3} / \mathrm{s}$ yang terjadi pada bulan April tahun 2018. 


\section{UCAPAN TERIMA KASIH}

Penulis mengucapkan terima kasih kepada Badan Pengelolaan Waduk Cirata (BPWC PT. PJB) yang telah membantu dalam penelitian ini serta semua pihak yang sudah membantu dalam kelancaran penelitian yang dilakukan.

\section{DAFTAR PUSTAKA}

1) Aditya Tsabitah, Indratmo Soekarno, Setio Wasito. (2017). Analisis Efektifitas Kegiatan Pengerukan Untuk Pengendalian Sedimentasi Waduk Cirata. MPSDA ITB.

2) DHI Water \& Environment. (2012). Mike 21 Flow Model FM, Hydrodynamics Module and Mud Transport Module. Scientific Documentation.

3) Chow, Ven Te. (1985). Hidrologi Saluran Terbuka, Penerbit Erlangga, Jakarta. 